in the room with the patient and stops the entrance of any gas which may possibly find its way through some overlooked crevice. During the preparation for disinfection the sanitary authorities make a thorough inspection and destroy any mosquito larvæ they find, pick up or destroy any vessels lying about which might serve as a receptacle for mosquito-breeding water, and close water boxes against the same danger. The patient remains in isolation for seven days, after which isolation may terminate if the family so wishes. The infected district is then treated as above indicated-that is, by disinfection, sanitary policing, and medical supervision. Disinfection is carried on in two ways, one force working from the centre toward the outer limits of the district and the other from the boundaries of the district inward. The area of infection being determined over as large an area as possible, these two sections separate, one of which begins immediately with the house in which the case of yellow fever occurred, the other beginning at those houses which might possibly have been infected at the greatest possible distance from the case in isolation. The purpose of such a system was to destroy all mosquitoes which might have carried infection within the district.

"While the disinfecting force is thus at work the police division, under the direction of a physician and of students who direct the different sections, operates throughout the infected district, making every effort to destroy all mosquito larvæ and to prevent the possible breeding of mosquitoes outside as well as inside the houses. Where larvæ are likely to exist in stagnant water or refuse of any sort, petroleum mixed with creoline, lysol, or similar products is thrown over the water or refuse in sufficient quantity to kill the larvæ instantly. Where it is impossible to use petroleum, as in the case of tanks and boxes for household use, a small fish, the 'barrigudo' or 'Girardinus caudimaculatus' is placed in large numbers in the water. This fish destroys the larvæ of mosquitoes most voraciously. Larvæ in the drains are destroyed by the use of Clayton gas, which is pumped into the sewer, which has been previously divided into compartments. Simultaneously with the disinfection the sanitary inspectors make daily inspection of the suspected district, examining every inhabitant supposed not to be immune-that is, children under five and all foreigners of less than five years' residence in Rio. These are subjected to the closest vigilance, being placed in isolation at the least tendency to rising tempera. ture. Reports are made in writing, those to whom this duty falls being required to fill up daily a bulletin sent out by the medical inspector to the chief of each district. In this report must be given the record of any who work outside the district, or who for any reason absent themselves therefrom, a record of their condition being also kept by the physician in the district in which they work or are temporarily resident. When any inhabitant absents himself from the district, the record must show his address, where he will be subjected to vigilance on the part of the authorities there. If the person under vigilance evades the attention of the physician and withdraws without giving notice, the owner of the house in which he lived is fined, he himself is apprehended by the sanitary police, fined, and subjected to renewed vigilance.

"Thus were carried out the details of the yellowfever campaign in this city. Those who are interested in the beginning of the campaign from the point of view of the above discussion and in the influence of the various factors in the development of the sanitary service as affecting yellow fever should read the important memorials of Dr. Bulhões de Carvalho, in "Contributions to the Epidemiological State of Yellow 'Fever,' Rio, I903, and of Oliveira Borges, in 'Prophylaxis of Yellow Fever in Rio de Janeiro,' presented to the Third Latin American Medical Congress in Montevideo, March 17 th to 23 rd, I907.

"In closing, we present below the statistics showing the death rate from yellow fever from I 872 to date, which serve to prove the statement in the beginning of this communication that yellow fever is wiped out in Rio de Janeiro."

Mortality from Yellow Fever in Rio de Janeiro

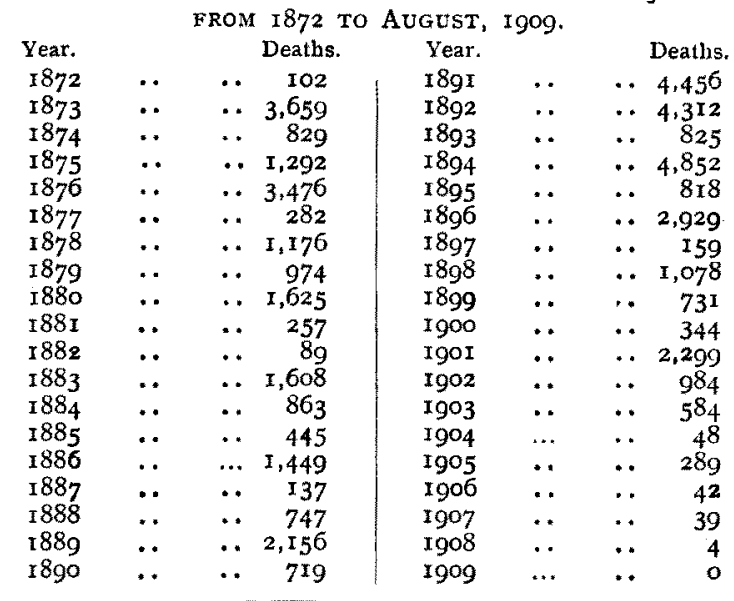

\section{DEATH CERTIFICATION.*}

BY MEREDITH YOUNG, M.D., D.P.H., County Medical Officer of Health, Cheshire,

Late Medical Officer of Health, Marylebone.

$\mathrm{I}^{\mathrm{T}}$ is really a matter of serious moment that the certification of causes of death is in such an unsatisfactory condition. Certification by medical men is on the whole quite satisfactory, and if the medical officer of health were given a proper locus standi so that he would be enabled, not merely as a matter of courtesy but as a matter of right, to inquire into cases where vague nomenclature had

*Annual Report, Marylebone, Igo8. 
been employed, and where primary causes were ineffectually distinguished from secondary causes, probably nothing more would be requisite. To this end little more is required but the transference of the supervision of registrars of births and deaths to the local sanitary authority, with power to make regulations for the guidance of these officers.

In the case of deaths not certified by medical practitioners a more drastic change is needed. 'The coroner's jury may have its good uses, but its seven hundred years of hoary antiquity must probably stand as one of the best excuses for its existence. A fairly extensive experience of such bodies compels me to say that, whilst innate common-sense and shrewdness often constitute their salvation from totally fallacious findings, they are exceedingly apt to be swayed more by irrelevant items of evidence than by those which are both relevant and admissible. Not infrequently their verdicts are arrived at without medical guidance, and are couched in terms which display a want of appreciation of the real meaning of the words they have heard and even of those which they have themselves used.

The law has in view, in the holding of coroner's inquests, the highly important duty of inquiring into cases of homicide or sudden death with the object of separating out those deaths due to criminal intent.

State medicine has in view an object no less important, for correct death certification depends upon correct medical nomenclature; upon the latter public health statistics are entirely based, and upon the last legislative measures for the betterment of public health are very largely founded.

There is a distinct necessity, in my opinion, for the regular co-operation of medical with legal knowledge in all inquiries into sudden and unknown causes of death. Every coroner possessed of legal qualifications alone should have as an adviser a medical man of extensive pathological experience, and post-mortem examination should be the necessary preliminary to every inquest. Until these essentials are carried out the findings of coroners' juries must be accepted with very considerable reserve. I give some verdicts recorded in this district during 1908 to show the curious wording sometimes adopted by juries :-

"Suffocation-want of fresh air, caused by collapse of houses."

"Bursting of abscess in abdomen and inflam. mation of lungs accelerated by fractured patella and injury to the side caused by a fall on ground when alighting from a tramcar in motion."

"Disease of heart and other organs caused by alcoholism, otherwise natural."

"Disease of heart and liver at a time when he was under chloroform for the purpose of an operation."
THE BILIARY CIRRHOSIS OF INEANTS, OTHERWISE KNOWN AS INFANTILE LIVER.*

By T. FREIK. PEARSE, M.D., M.R.C.P., D.P.H., Health Officer, Calcutta.

FOR many years a peculiar disease of the liver of infants, accompanied with fever and attended with a high mortality, has been recognized in India (Bengal).

The morbid anatomy and pathology of this disease were well described by Lieut.-Colonel Gibbons, I.M.S. (retired), in $189 \mathrm{I}$, who considered it a form of biliary cirrhosis, and suggested that the term intercellular cirrhosis would be appropriate, as there occurred a primary development of fibrous connective tissue within the lobules between the liver cells. The other organs of the body seem unaffected, except the kidney, which shows marked degeneration and shedding of the epithelium of the tubules. The usual post-mortem appearances were cedema of feet and legs and generally of face and hands, and a small quantity of fluid in the abdomen. All the tissues of the body are bile-stained. In the earlier stages the liver is enlarged, but later it becomes small. There is no perihepatitis, but the liver substance is tough and the outer surface granular. The liver cells are much altered, many being destroyed and others converted into masses of granular débris. In the interlobular band of connective tissue many bile ducts are found. The intercellular fibres are not applied closely to the degenerated cells, but form a network, in the spaces of which the degene. rated cells lie.

It was suggested that the disease is due to an irritant which primarily attacks the liver cells, but which also leads to proliferation of the connective tissue elements. The proliferation of the bile ducts is not so easily explained, but it was suggested by Paltang to be a curative process, in which a regeneration is brought about by a multiplication of bile ducts from which masses of liver cells were formed. The disease is not due to alcohol, there is no evidence of syphilis, and the pathological changes are quite different from the liver enlargement which follows malaria.

Symptoms.-The disease is almost entirely limited to children between six months and two years of age. The onset is insidious. Some families seem liable to the disease. It occurs amongst rich and poor, but is probably less common amongst Mahomedans than Hindus. It is as common amongst infants fed with other milk than that of their mothers.

The disease varies in its duration, sumetimes lasting a month only, at others for perbaps two years. Generally the first symptom noticed is enlargementf o the liver, but earlier symptoms are

$$
\text { * Annual Report, } 1908 .
$$

